\title{
Summer School on Intelligent Agents in Automation: Experience and Reflections from the Second Edition
}

\author{
Luis Ribeiro*, Paulo Leitão ${ }^{\dagger \ddagger}$, Birgit Vogel-Heuser ${ }^{\S}$ and José Barata 9 \\ * Linköping University, Linköping University SE-58 183, Linköping, Sweden, Email: luis.ribeiro@liu.se \\ †Polytechnic Institute of Bragança, Campus Sta Apolónia, 5300-253 Bragança, Portugal, Email: pleitao@ipb.pt \\ $\ddagger$ LIACC - Artificial Intelligence and Computer Science Laboratory, Rua Campo Alegre 1021, 4169-007 Porto, Portugal \\ §Technical University of Munich, Boltzmannstraße 15, 85748 Garching near Munich, Germany, Email: vogel-heuser@tum.de

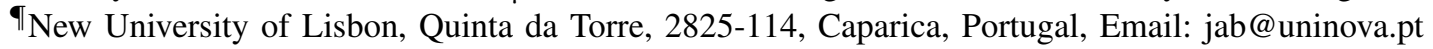

\begin{abstract}
Several research agendas worldwide are targeting the development of Industrial Cyber-physical Systems as the next generation of intelligent embedded devices with improved interaction capabilities. These devices, and their potential uses, are though to deliver a radical increase in system sustainability, reconfigurability and flexibility which is perceived to be the root of the so called $4^{\text {th }}$ Industrial Revolution. However such technical systems, at the envisioned revolutionary scale, do not exist just yet and require a convergent and multidisciplinary research and development efforts. The academia curricula are also, albeit slowly, adjusting to the emerging education requirements. The Summer School on Intelligent Agents in Automation is a joint effort from several researchers in core areas of the $4^{\text {th }}$ Industrial Revolution landscape to close the gap and promote advanced education in this context. This paper describes the implementation of the $2^{\text {nd }}$ edition of the event as well as the experience and reflections resultant from it.
\end{abstract}

Index Terms-Summer School, Cyber-Physical Systems, Agent-based Systems, Service-based Systems, Industrial Automation, Modeling

\section{INTRODUCTION}

Cyber-physical Systems (CPSs) is the designation attributed to the next generation of intelligent embedded systems with improved interaction capabilities. Despite the many nuanced definitions [1], the idea of a logical representation unified with a mechatronic aggregate and acting on behalf of this whole seems to consistently be agreed upon. Collectively the developments supporting CPSs cut with traditional system design rules by removing predefined communication patterns and tight logical couplings and increasingly relying in the establishment of dynamic interactions between more autonomous components in a system.

The modular, autonomous and self-contained nature of cyber-physically formulated equipment provides an automation solution developed upon this premises with an important advantage in respect to reconfigurability, adaptiveness and robustness as well as important gains in overall sustainability. This comes on a par with the possibility of establishing new business models whereby industrial equipment can be integrated almost instantly to tackle volatile business opportunities and subsequently disconnected and moved to another plant once the production targets have been fulfilled.

This motivation can be seen in the rationale for several international research agendas including but not limited to [2]: the H2020 Framework Programme for Research and Innovation under the Factories of the Future public-private partnership (EU); the Industrial Internet Consortium, created by AT\&T, Cisco Systems, General Electric, IBM and Intel in 2014 (US), the Made in China 2025 initiative (CN) and globally many other initiatives.

However the design of cyber-physical automation solutions is characterized by a plethora of challenges ranging from the maturity of the support technologies [3], [4] to the lack of design, modeling and validation guidelines [5], [6]. Most of the conceptual barriers are well known in the domains of agentbased and holonic manufacturing systems which are in fact precursors of what is now starting to be known as CyberPhysical Production Systems (CPPSs). These barriers, some of which have been present since the inception of these research areas, include but are not limited to [7]: establishing the granularity and modularity boundaries of the system modules and their actuation scope, understanding the system composition/aggregation rules and style (structural or logic), managing the cyber-physical identity across different technological platforms, both hardware and software, with multiple form factors and varying computational capabilities/characteristics, etc.

Such challenges are difficult enough for seasoned researchers which renders them fairly overwhelming for anyone else trying to grasp both the technological and conceptual framework of the research in CPPSs. The summer school documented in this paper is an attempt to facilitate such introduction by providing an integrated and practical view on most of these aspects. In particular, it aims at showing the link between advanced AI concepts such as agency and service-orientation and the prevailing shop-floor technologies 
still dominated by traditional Programmable Logic Controllers (PLCs) and the programming languages defined in the IEC 61131-3 standard along with a set of potential modeling and integration strategies.

The previous rational has been at the inception of the Summer School on Intelligent Agents in Automation whose $1^{\text {st }}$ edition, documented in [2], happened in 2015 at the campus of the New University of Lisbon, in Portugal with the technical support of the IEEE IES Technical Committee on Industrial Agents, Linköping University, Polytechnic Institute of Bragança, New University of Lisbon and the Technical University of Munich.

The $2^{\text {nd }}$ edition, held in 2016 at the Valla campus of Linköping University had, in addition the previous supporting institution and organs, the support of the Swedish P2030 Instrument of Education through its graduate school. This edition, developed under the thematic "The 4th Industrial Revolution and the Industrial Internet of Things" introduced several changes in the event's structure designed both for students that had no previous knowledge and students from the $1^{\text {st }}$ edition interested in honing their skills. The main learning outcomes of this edition were to:

- Discuss the vision and the main challenges related to the fourth industrial revolution (also known as Industry 4.0) and the main research initiatives in this area;

- Understand the main design and implementation principles that support cyber-physical production system and the system that motivate Industry 4.0;

- Understand why a cyber-physical system is different from todays conventional system;

- Understand the requirements on the computational and physical infrastructures required to support such a system;

- Design a simple cyber-physical production system;

- Use at a basic level the main technologies supporting such systems;

- Understand how to use todays technologies to create an industrial cyber-physical system;

- Use Intelligent Agents as a mechanism to design the cyber part of a cyber-physical system.

Similarly to the $1^{\text {st }}$ edition, the different topic leading to these learning outcomes where lectured by internationally well-known researchers in their fields. All the theoretical lectures were supported by substantial hands-on exercises with commercial-off-the-shelve state-of-the-art technologies and two industrial keynote speeches focusing on the technical and the social implications of these emerging systems where delivered.

The subsequent details are organized as follows: section II describes the organization of the event, section III describes the content of the lectured modules, section IV details the technical infrastructure and project, section $\mathrm{V}$ reflects on the experiences and student's perceptions and feedback, finally section VI round up the paper with the conclusions.

\section{Pedagogical Methodology}

The $2^{\text {nd }}$ edition targeted advanced practitioners from industry and academia and graduate level students (typically $\mathrm{PhD}$ ) with different backgrounds. This event was also incorporated as an official doctoral course at Linköping University and as part of the course portfolio for 2016 of the Swedish Production Academy graduate school (both examined separately). The schedule included $2+5$ days worth of different modules. The first 2 days (Fig. 1) consisted of a basic introductory course to agent based programming using JADE [8] while the subsequent 5 days constituted the main part of the course and featured two parallel tracks (Figs. 2 and 3).

\begin{tabular}{|c|c|}
\hline Thursday, 9th of June 2016 & Friday, 10th of June 2016 \\
\hline Registration & \multirow{2}{*}{ Introduction to Agent programming with JADE } \\
\hline $\begin{array}{c}\text { Welcome to the Introductory Course } \\
\text { Introduction to the JAVA programming language to } \\
\text { support the basics of agent programming }\end{array}$ & \\
\hline Lunch Break & Lunch Break \\
\hline $\begin{array}{c}\text { Introduction to the JAVA programming language to } \\
\text { support the basics of agent programming }\end{array}$ & Introduction to Agent programming with JADE \\
\hline
\end{tabular}

Fig. 1. Schedule of the Introductory Course

\begin{tabular}{|c|c|c|c|c|}
\hline $\begin{array}{c}\text { Monday the 13th } \\
\text { of June } 2016\end{array}$ & \begin{tabular}{|c|}
$\begin{array}{c}\text { Tuesday the } 14 \text { th } \\
\text { of June } 2016\end{array}$ \\
\end{tabular} & \begin{tabular}{|c|} 
Wednesday the \\
15 th of June 2016
\end{tabular} & \begin{tabular}{|c|} 
Thursday the \\
16 th of June 2016
\end{tabular} & \begin{tabular}{|c|} 
Friday the 17 th of \\
June 2016
\end{tabular} \\
\hline Registration & \multirow{4}{*}{ Industrial Agents } & \multirow{3}{*}{\begin{tabular}{|c|} 
Keynote 1 \\
Humans the next \\
generation \\
mechatronic \\
devices for \\
Industry 4.0? \\
\end{tabular}} & \multirow{3}{*}{$\begin{array}{c}\text { Keynote 2 } \\
\text { Towards the loT } \\
\text { Data-Driven } \\
\text { Enterprise }\end{array}$} & \multirow{4}{*}{ Project } \\
\hline $\begin{array}{c}\text { Welcome to the } \\
\text { main Course }\end{array}$ & & & & \\
\hline \multirow[b]{2}{*}{$\begin{array}{l}\text { Introduction to } \\
\text { Ontologies in a } \\
\text { Production } \\
\text { Context }\end{array}$} & & & & \\
\hline & & \begin{tabular}{|c|} 
Model-driven \\
Engineering and \\
implementation \\
of field level \\
agents with \\
IEC61131-3 \\
\end{tabular} & Networking & \\
\hline Lunch Break & Lunch Break & Lunch Break & Lunch Break & Lunch Break \\
\hline $\begin{array}{c}\text { Design, } \\
\text { Deployment and } \\
\text { Development of } \\
\text { Agent-based } \\
\text { Production } \\
\text { Systems } \\
\end{array}$ & $\begin{array}{c}\text { Designing and } \\
\text { implementing } \\
\text { field level agents } \\
\text { with IEC } 61499\end{array}$ & Project & Project & Closing Session \\
\hline
\end{tabular}

Fig. 2. Schedule of the Basic Course

The modules where therefore organized along three main learning paths:

- Beginner - introductory agent programming course and the basic track (compulsory for students enrolled through the $\mathrm{PhD}$ program at Linkping University as well as from the Swedish Production Academy graduate school);

- Starting - main part of the course on the basic track for students with previous programming experience;

- Advanced - main part of the course on the advanced track for students that had taken the previous version of the course on the basic track.

The size of the modules was typically 3,5 hours including both the theoretical and practical components with an 


\begin{tabular}{|c|c|c|c|c|}
\hline $\begin{array}{c}\text { Monday the 13th } \\
\text { of June } 2016\end{array}$ & \begin{tabular}{|c|}
$\begin{array}{c}\text { Tuesday the } 14 \text { th } \\
\text { of June } 2016\end{array}$ \\
\end{tabular} & \begin{tabular}{|c|} 
Wednesday the \\
15 th of June 2016
\end{tabular} & $\begin{array}{c}\text { Thursday the } \\
\text { 16th of June } 2016\end{array}$ & $\begin{array}{c}\text { Friday the } 17 \text { th of } \\
\text { June } 2016\end{array}$ \\
\hline \multicolumn{5}{|c|}{\begin{tabular}{|l|l|l|l} 
Registration & & & \\
\end{tabular}} \\
\hline $\begin{array}{c}\text { Welcome to the } \\
\text { main Course }\end{array}$ & \multirow{3}{*}{$\begin{array}{l}\text { Advanced topics } \\
\text { in field level } \\
\text { agents }\end{array}$} & \multirow{2}{*}{$\begin{array}{c}\text { Keynote } 1 \\
\text { Humans the next } \\
\text { generation } \\
\text { mechatronic } \\
\text { devices for } \\
\text { Industry } 4.0 ? \\
\end{array}$} & \multirow{2}{*}{$\begin{array}{c}\text { Keynote } 2 \\
\text { Towards the loT } \\
\text { Data-Driven } \\
\text { Enterprise }\end{array}$} & \multirow{3}{*}{ Project } \\
\hline \multirow[t]{2}{*}{$\begin{array}{c}\text { Advanced aspects } \\
\text { of agent to legacy } \\
\text { system } \\
\text { integration }\end{array}$} & & & & \\
\hline & & Project & Networking & \\
\hline Lunch Break & Lunch Break & Lunch Break & Lunch Break & Lunch Break \\
\hline \multirow[t]{2}{*}{$\begin{array}{l}\text { Agent-based } \\
\text { modelling and } \\
\text { Simulation }\end{array}$} & \multirow[t]{2}{*}{$\begin{array}{l}\text { Axiomatic Design } \\
\text { of Large and } \\
\text { Complex } \\
\text { Industrial } \\
\text { Systems }\end{array}$} & \begin{tabular}{|c|}
\multicolumn{1}{|c|}{ Advanced } \\
Aspects on \\
Model-driven \\
Engineering and \\
implementation \\
of field level \\
agents with \\
IEC61131-3 \\
\end{tabular} & Project & \multirow[t]{2}{*}{$\begin{array}{l}\text { Closing Session } \\
\text { and End of Day } 5\end{array}$} \\
\hline & & Project & Project & \\
\hline
\end{tabular}

Fig. 3. Schedule of the Advanced Course

prevalence of the practical component allowing the students to have at least 2 hours of hands-on experience. This experience was subsequently put to a test in the form of a collaborative CPPS design and implementation project to be developed autonomously by the students.

The industrial perspective on the course related developments was supported by two keynotes and consolidated in networking session that promoted the interaction and the exchange of experiences, ideas and challenges between students, lecturers and speakers.

All the learning materials where delivered through and online platform which was actively used both by the lecturers and the students to deploy/retrieve updated material as the theoretical and practical parts of the modules developed. This on-line platform was particularly important during the Project as it enabled sharing the updating and merging the different software contributions of the students working collaboratively.

\section{COURSE CONTENTS}

This edition of the summer school includes most of the material already described in [2]. The reader is referred to this previous work to learn about the contents of the basic track. In this context, this section focuses mainly on the newly developed materials for the Advanced track as well as for the Introductory course. The main motivation for these changes was on the one side, the strong intention of the students from the first edition to retake the course to learn to improve their knowledge in more advanced topics and on the other side, the identified need to improve on specific programming requisites.

\section{A. Introductory Course}

This part of the course had two main learning moments (Fig. 1). The first day was devoted to introducing the students to the most relevant JAVA programming techniques and data structures that are important for understanding the main programming patterns in JADE. The student also had the first contact with the software libraries that they would later used for interacting with the educational system to be automated as part of the project work.

The second day focused on introducing the students to multi-agent-based programming using JADE. This session included a description of the technical architecture of a multiagent system implemented with JADE as well as the main tools that are available in the platform (discovery services, debugging and visualization, management and environment control). The main design principles for behavior-based agents, including the usage of the different standard behaviors and the typical programming patterns and their implications, were also exposed and clarified.

The Introductory Course was lectured by Luis Ribeiro from Linköping University, Sweden.

\section{B. Advanced Track}

The Advanced Track included 5 distinct modules as detailed in the following subsections.

1) Advanced Aspects of Agent to Legacy System Integration: The objective of this module was to introduce the students to the design of high level Hardware Abstraction Layers (HALs) as software harmonizing layers that enable the seamless integration of the cyber component of a CPS with its physical counterpart. The module focused on:

- The definition of software interfaces and their metalanguage description on the agent side and the corresponding implementation libraries on the equipment/legacy controller side;

- Programming techniques using the JAVA reflection API to dynamically load these implementation libraries in runtime;

- Design an performance considerations.

This module was lectured by Luis Ribeiro from Linköping University, Sweden, and the basic material discussed in this module can be found in [9]

2) Agent-based Modeling and Simulation: The objective of this module was to provide hands-on knowledge on AgentBased Modeling and Simulation tools (ABMS), which are used to model and simulate complex systems that evolve over time. For this purpose, this module included an introduction to ABMS, particularly NetLogo, to develop practical examples of such systems in the manufacturing domain. The module focused on:

- Introduction to ABMS, namely definition, objectives, agent-based model, simulation, notion of time in simulation, brief description of existing ABMs tools;

- Introduction to the NetLogo tool, focusing the navigation in the tool, notion of turtles, patches and links, and illustration of a simple example.

- Implementation of a practical and extended example in NetLogo.

This module was prepared by Paulo Leitão and Joseé Barbosa from the Polytechnic Institute of Bragança, Portugal, and lectured by José Barbosa.The basic material discussed in this module can be found in [10]. 
3) Advanced Topics in Field-level Agents: The objective of this module was to introduce the students to advanced programming aspects with the IEC61499 towards the creation of distributed automation and control systems The module focused on providing a comprehensive overview of the IEC 61499 standard with a main focus on reconfigurability on the field level as well as the discussion of implemented scenarios in industry and research.

This module was lectured by Thomas Strasser from the Austrian Institute of technology, Austria, and the basic material discussed in this module can be found in [11].

4) Axiomatic Design of Large and Complex Industrial System: The objective of this module was to introduce the students to Axiomatic Design as a hetero-functional graph theory which may be applied to cyber-physical engineering systems. Such an approach has the advantage of providing a quantitative framework that can inform the different stages of the system design. The module focused on:

- Engineering large complex engineering systems;

- Axiomatic Design, Model-Based Systems Engineering and Graph Theory;

- System Structure: Axiomatic Design as a Heterofunctional Graph Theory;

- System Behavior: The Imposition of Static and Dynamic device models;

- Multi-Agent Systems: Design Principles for Resilient Reference Architectures.

This module was lectured by Amro F. Farid from the Thayer School of Engineering at Dartmouth, US, and the basic material discussed in this module can be found in [6], [12].

5) Advanced Aspects on Model-driven Engineering and Implementation of Field-level Agents with IEC61131-3: The objective of this module was to introduce the characteristics and development of field level agents for CPPS that need to fulfill reliability and real-time requirements. (The concepts were demonstrated for system reconfiguration in case of a faulty sensor, redirection of products in case of a faulty belt component and rescheduling of production jobs to other plant in case of a faulty plant.) The module focused on: Challenges for Field level agents in automation Concept of PLC-based agents for CPPS with synchronous programming Model based engineering using SysML and code generation to IEC 611313 Description of agents' knowledge using OCL Metrics for adaptivity of such CPPS. This module was lectured by Birgit Vogel-Heuser from the Technical University of Munich, Germany, and the basic material can be found in [13], [14]

\section{Industrial Keynote Speeches}

The Summer School featured two industrial keynote speeches focusing on highly complementary core topics of the $4^{\text {th }}$ Industrial Revolution. In this context, the the first keynote speech focused on the socio-technical implication of these new emerging technologies while the second focused on the industrial technological and business perspective. The summary of both speeches are provided by their authors are quoted below:
1) Humans the next generation mechatronic devices for Industry 4.0?: I think in decentralized control one has to be aware of the decision mechanisms. Control is granted to other parts of the system without any condition. If one understands these mechanisms they can be applied not only to technical systems but also to organizations and administrations. This could lead to improved conditions for employing people, more people instead of less. At the same time there is a research approach to improve the situation of humans in manufacturing by regarding them basically as an asset that needs mock up by augmented reality, by psychometric measurements, by some additional controllers and/or by improvement of the ergonomic environment. I want to draw the students attention to the fact that they for themselves have to take an active decision what road to follow for themselves in their respective work and what consequences this may have.

This speech was delivered by Christoph Hanisch formerly from Corporate Research and Technology of Festo AG \& Co, Germany.

2) Towards the IoT Data-Driven Enterprise: "Modern enterprises need to be agile and dynamically support decision making processes at several levels. To achieve that, critical information acquired from the field as well as intra- and inter-organizational business processes need to be available at the right point in a timely manner, and in the right form. Collecting and processing huge amounts of data is therefore in the core of the emerging industrial infrastructure. Especially with the emergence of Cyber-Physical Systems, Service Oriented Architectures, the Cloud, and Big Data, the way enterprise applications and services are designed, developed, and utilized is drastically changing. The lecture will provide insights on these emerging technologies, their challenges and their application in industrial automation and smart grids."

This speech was delivered by Stamatis Karnouskos from SAP, Germany.

\section{TEChNiCAL Infrastructure AND ProJect}

\section{A. Technical Infrastructure}

Towards the end of the course, all the students irrespectively of the their path in the Summer School were challenged to develop in a collaborative way a cyber-physical solution for the automation of a didactic production system. The system, detailed in Fig. 4, is composed of two subsystems: a transport system with an overhead crane and a manual station and a storage system. The first subsystem is controlled from two networked PLCs while the second from a single PLC. All the PLC use CODESYS and subsequently support all the languages from the IEC61131-3. They are also connected, as part of the same network, to a wireless router. The students got detailed explanation of the infrastructure and were given a JAVA library that abstracts the communication with the PLC.

Such an approach has the additional pedagogical value of highlighting the possibilities of cloud based control by emulating a local cloud whereby the cyber-part runs from the students computers and is physically separated from the me- 


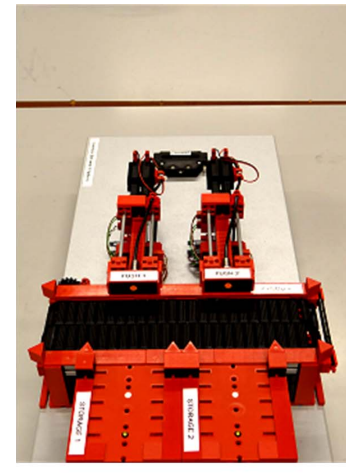

a)

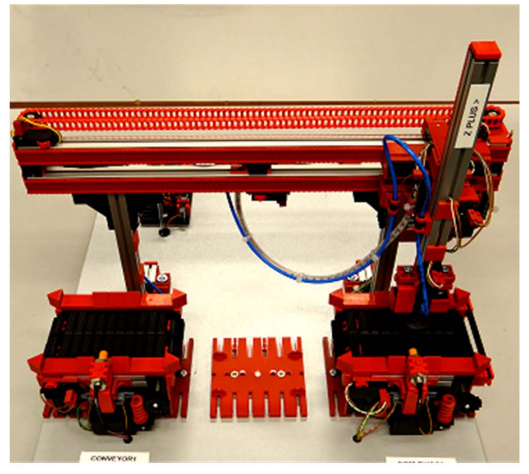

b)
Fig. 4. The didactic manufacturing system used in the course composed of two modular subsystems: a) storage system and b) transport system with overhead crane

chanical part. At the same time a cyber-physical relationship is established and maintained throughout the system's operation.

\section{B. The Project}

The students where asked to spontaneously form smaller teams with a good mix of members' skills and background and where subsequently challenge to create and implement a basic CPS architecture to control both subsystems. They had to demonstrate that their architecture could support plug and produce and adaptive response, emulated by exchanging the order of the subsystems, without any further need for reprogramming. The final solution should consists on the conceptual/architectural modeling of the system and a follow-up implementation. Such an approach had as objective to confront the students with the complexity of implementing solutions that on a conceptual plane seem sometimes deceivingly simple.

\section{REFLECTIONS AND EXPERIENCE}

Overall 20 students and 9 lecturers/speaker participated in the event. The students, mainly at $\mathrm{PhD}$ level, had a mixed background which included both: electrical, mechanical and production engineers as well as computer scientists; and originated from 5 different countries as detailed in Fig. 5

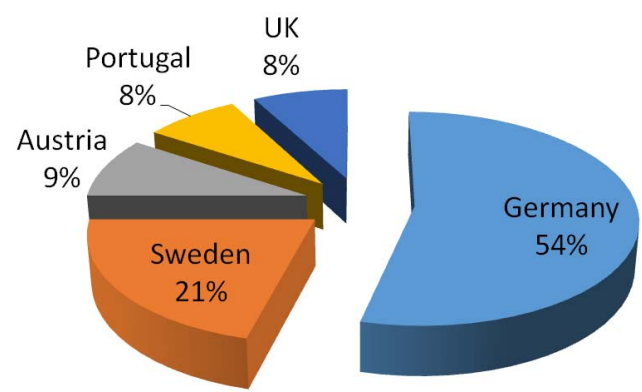

Fig. 5. Student Attendance by Country (the values are rounded to the unit)
Out of the 20 students, 5 have enrolled in the advanced course and 15 on the basic course. Interestingly though 3 of the students in the advanced track asked to join the introductory course as well. This is a clear indication that some of the technical knowledge required for the implementation of CPPSs is not widely available yet.

At the end of the summer school, the students were invited to answer an anonymous questionnaire designed to capture their perception on organizational aspects, the teaching/learning environment and outcomes, and future editions of the event. The questionnaire used the Likert scale for the majority of the answers whereby the students had to provided their degree of satisfaction. All the students have replied to the questionnaire. Collectively the answers are conclusive in a number of factors.

Despite the Summer school having been publicized in a number of public websites, students heard about it mainly from colleagues of their research supervisors. This is coincident with the high degree of motivation to enroll in some of the main core components in the course Fig. 6.

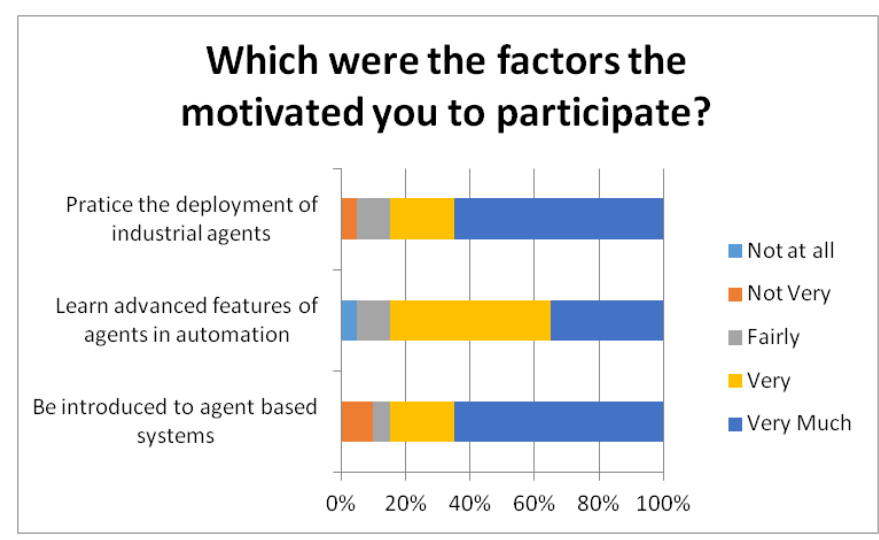

Fig. 6. Motivation Factors

In relation to the data reported in [2] more students (50\%) claimed that their efforts in the course would be recognized by their institution. Among the other students, 4 were sure that they would not have any recognition. This increase in recognition can be explained by the fact that all the Swedish students enrolled either through the doctoral program at Linköping University or through the Swedish Production Academy graduate school, both of which grant immediate recognition, albeit requiring separate examination. In these cases the students were credited 6 ECTS for participating in the course and submitting a written report summarizing the main aspects learned.

Overall, the students were (more than 50\%) either very or very much satisfied with the duration and dates of the event. They were also very pleased with the quality of the academic and pedagogical activities (Fig. 7).

The degree of satisfaction with the quality of the teaching and the lectures was very high, on a part with the results of the previous edition. There was also a slight improvement in the satisfaction related to the equipment used, required 


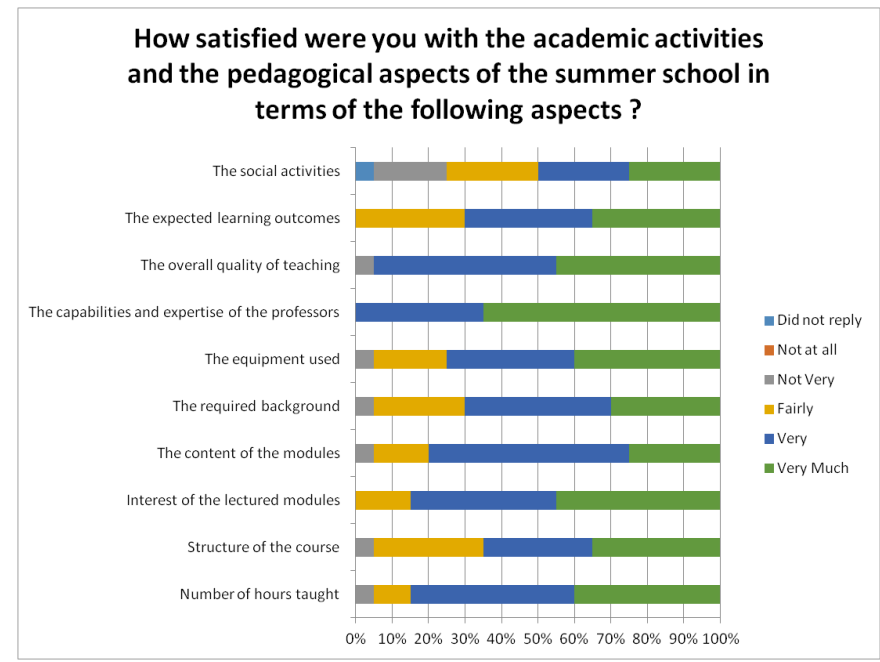

Fig. 7. Overall Degree of Satisfaction

background and interest of the lectured modules.

The biggest decline in quality seems to be related to the social activities of the event, even if these activities where comparable in number and quality to the ones of the previous edition. The high participation of Swedish students might have reduced the surprise effect/satisfaction related to the social program.

$40 \%$ of the students gave a overall score of Excellent to the course and and 55\% scored it as Good. One student scored the course as Not Enough. These figures denote a relevant improvement in respect to the previous edition (25\% Excellent, $75 \%$ Good). We attribute the improved score to the decisions of specializing the tracks and the modification in the introductory part of the course which, in all, made the course more comprehensive and tailored to the different students' needs.

Finally, all the students would recommend the course to a colleague. Half of them would recommend it very much while $35 \%$ would recommend it very and the others fairly. These numbers are aligned with the students perception that the course is in general relevant for their future career/developments (Fig. 8).

\section{CONCLUSION}

This paper reflects the experiences resulting from the implementation of second edition of the summer school on intelligent agents in automation. The pertinence of the course is clear from the student participation and positive feedback. Their feedback is also an indication that the course if filling an important gap in post-graduate education that requires joint multidisciplinary developments that are otherwise difficult to attain in a more conventional academic setup.The fact that this year's edition counted with participants from the previous one, seeking yet more advanced courses, also shows that there is need a more continuous education in the area. Finally, and maybe foremost, several discussion with the participants during the event highlighted that this event also has an important

\section{Do you think the participation in the course will help you with...}

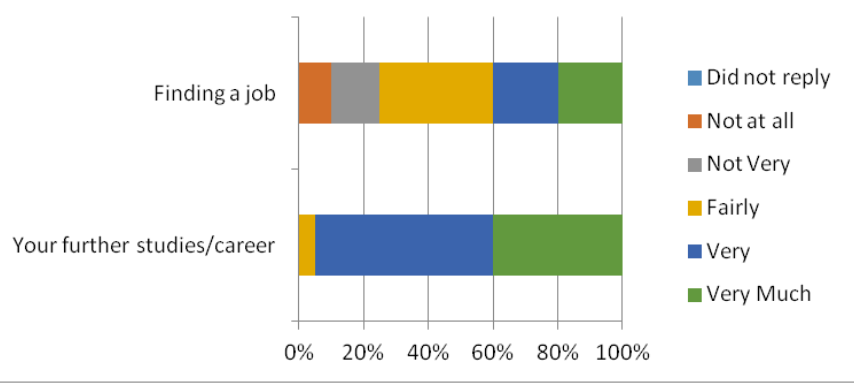

Fig. 8. Career/Future expectations in relation to the course contents

community building mission/effect which is, together with the computed statistics and indication that the social activities do play an important, unspoken role.

\section{REFERENCES}

[1] L. Miclea and T. Sanislav, "About dependability in cyber-physical systems," in Design \& Test Symposium (EWDTS), 2011 9th East-West. IEEE, 2011, pp. 17-21.

[2] P. Leitão, L. Ribeiro, J. Barata, and B. Vogel-Heuser, "Summer school on intelligent agents in automation: Hands-on educational experience on deploying industrial agents," in Industrial Electronics Society, IECON 2016-42nd Annual Conference of the IEEE. IEEE, 2016, pp. 66026607.

[3] P. Leitão, "Agent-based distributed manufacturing control: A stateof-the-art survey," Engineering Applications of Artificial Intelligence, vol. 22, no. 7, pp. 979-991, 2009.

[4] V. Marik and D. McFarlane, "Industrial adoption of agent-based technologies," IEEE Intelligent Systems, vol. 20, no. 1, pp. 27-35, 2005.

[5] A. M. Farid, "Measures of reconfigurability and its key characteristics in intelligent manufacturing systems," Journal of Intelligent Manufacturing, vol. 1, pp. 1-17, 2014

[6] A. M. Farid and L. Ribeiro, "An axiomatic design of a multiagent reconfigurable mechatronic system architecture," IEEE Transactions on Industrial Informatics, vol. 11, no. 5, pp. 1142-1155, 2015.

[7] L. Ribeiro, "Cyber-physical production systems design challenges," in IEEE International Symposium on Industrial Electronics, 2017.

[8] F. L. Bellifemine, G. Caire, and D. Greenwood, Developing multi-agent systems with JADE. John Wiley \& Sons, 2007, vol. 7.

[9] L. Ribeiro and P. Linder, "Hardware abstraction layer for java-based agents," in Proceedings of the Annual Conference of IEEE Industrial Electronics Society, 2016.

[10] J. Barbosa and P. Leitão, "Simulation of multi-agent manufacturing systems using agent-based modelling platforms," in Proceedings of the 9th IEEE International Conference on Industrial Informatics (INDIN11), 2011, pp. 477-482.

[11] T. Strasser, M. Rooker, G. Ebenhofer, A. Zoitl, C. Sunder, A. Valentini, and A. Martel, "Framework for distributed industrial automation and control (4diac)," in Industrial Informatics, 2008. INDIN 2008. 6th IEEE International Conference on. IEEE, 2008, pp. 283-288.

[12] A. M. Farid, "An engineering systems introduction to axiomatic design," in Axiomatic Design in Large Systems. Springer, 2016, pp. 3-47.

[13] P. Hehenberger, B. Vogel-Heuser, D. Bradley, B. Eynard, T. Tomiyama, and S. Achiche, "Design, modelling, simulation and integration of cyber physical systems: Methods and applications," Computers in Industry, vol. 82, pp. 273-289, 2016.

[14] B. Vogel-Heuser, D. Witsch, and U. Katzke, "Automatic code generation from a uml model to iec 61131-3 and system configuration tools," in Control and Automation, 2005. ICCA'05. International Conference on, vol. 2. IEEE, 2005, pp. 1034-1039. 